\title{
Construindo o currículo no cotidiano de um curso de graduação em medicina
}

\author{
Building the undergraduate medicine course curriculum \\ La construcción de una innovación curricular de un curso de pregrado en medicina
}

O curso de Medicina da Faculdade de Ciências Médicas de Sorocaba, a exemplo de outros cursos, estava empenhado em discussões para a alteração do seu projeto pedagógico desde a nomeação de uma comissão de reforma curricular, em 2001. Pouco tempo depois, em março de 2002, os Ministérios da Educação e da Saúde convidaram as escolas de medicina a responderem o edital para seleção dos melhores projetos de reforma curricular, iniciativa que deu origem ao Programa de Incentivo a Mudanças Curriculares nos Cursos de Medicina (PROMED). A escolha final ocorreu no início de novembro de 2002, e vinte instituições de ensino superior foram selecionadas, entre elas a Faculdade de Ciências Médicas de Sorocaba. Em outubro de 2005, a proposta de reformulação do projeto pedagógico é apresentada aos alunos e professores da faculdade. Com a proposta concluída, começou a tramitação formal nas instâncias acadêmicas da universidade onde foi aprovada no final do ano de 2005. Em 2006, ela foi implementada para os alunos ingressantes naquele ano. O objetivo dessa pesquisa foi investigar o processo de formulação e implementação da nova proposta curricular para o curso de Medicina de Sorocaba. Ao decidir perscrutar o processo de inovação curricular, procurei apoiar-me em pesquisas que consideram que há possibilidade de conhecermos a escola a partir do seu cotidiano, e que, para isso, é necessário mergulhar na vida cotidiana considerando a relevância dos elementos que a constituem, acreditando que a possibilidade de ruptura com nossos saberes prévios, nossas certezas, nossos pré-conceitos a respeito da realidade poderá nos fazer compreender o currículo real, aquele que se constrói no cotidiano de cada uma das escolas de medicina. Investigar o processo de implementação do novo currículo da Faculdade de Medicina de Sorocaba demandou a escolha de uma abordagem de avaliação entendida, essencialmente, em sua função formativa, cujo objetivo foi abrir espaço de diálogo e trocas. A opção metodológica pela pesquisa qualitativa nos permitiu analisar os significados que os indivíduos, sujeitos dessa pesquisa, deram às suas ações. Sendo assim, ela pode ser caracterizada como um estudo de caso do tipo etnográfico, que privilegiou, como técnicas para a coleta de dados: a observação participante, a entrevista e a utilização de fontes documentais. A análise do Discurso do Sujeito Coletivo foi o recurso metodológico escolhido para analisar os depoimentos coletados nas entrevistas. Também utilizei outras fontes de dados, como o diário de campo e fontes documentais, visando a um processo de triangulação. O produto de um processo de mudança curricular é tanto o currículo materializado em um plano, como a sua construção cotidiana e a aprendizagem permanente de alunos, professores, administradores, enfim, de todos os participantes, visando ao aperfeiçoamento contínuo da ação educativa. Produto que foi sendo tecido no cotidiano da faculdade, no enfrentamento das dificuldades e dos desafios que uma reformulação curricular desse porte ocasiona.

\section{Maria do Carmo Abib de Moraes Polimeno Tese (Doutorado), 2010 \\ Programa de Pós-Graduação em Educação, Pontifícia Universidade Católica de São Paulo mariado@uol.com.br}

Palavras-chave: Educação médica. Inovação curricular. Avaliação. Keywords: Medical education. Curricular innovation. Assessment. Palabras clave: Educación médica. Innovación curricular. Evaluación.

Texto na íntegra disponível em: <http://www.sapientia.pucsp.br/> 


\title{
Mulheres, saúde e grupalidade: estudo do grupo de Convivência Reviver, Botucatu, SP
}

\author{
Women, health and group: study of Reviver social group, Botucatu, SP \\ Mujeres, salud y grupo: estudio de grupo de convivencia Reviver, Botucatu, SP
}

As atividades grupais estão presentes em várias áreas do conhecimento e têm sido uma importante ferramenta na Atenção Primária à Saúde. Quando entendido como processo, o grupo pode representar a resistência aos modos individualizantes, pode atuar como um dispositivo capaz de construir modos de subjetividade singulares. O presente trabalho descreveu e analisou a experiência de um grupo de vivência de mulheres enquanto espaço de produção de desejos, desmistificando modos de ser e de viver. $A$ investigação, de natureza qualitativa, foi conduzida com as integrantes do grupo de convivência Reviver, constituído por senhoras na faixa dos 50 anos ou mais. O grupo começou em 1999, tendo como público-alvo usuárias da área de saúde mental do Centro de Saúde Escola (CSE), da Faculdade de Medicina de Botucatu da Universidade Estadual Paulista (UNESP); e, como proposta, ser um espaço de promoção da saúde e de lazer. Inicialmente, eram encaminhadas pelo CSE, mas, com o fortalecimento do grupo, as próprias participantes começaram, também, a convidar amigas e familiares. As técnicas de coleta utilizadas foram: observação participante, entrevista com formuladores do grupo, e entrevistas baseadas nas histórias de vida de cinco mulheres. As histórias de vida foram transcritas e estudadas mediante análise temática de conteúdo. Os núcleos temáticos foram identificados segundo os diferentes ciclos da vida, tendo como mais relevantes: na infância e juventude (as dificuldades financeiras e a violência) e na vida de casada ("o lugar de mulher é dentro de casa", laços sociais fragilizados, dificuldades financeiras, experiências de violência e a ajuda profissional). Reconheceram-se, ainda, os núcleos temáticos significativos relativos à vivência do grupo Reviver, quais sejam: as experiências que levaram ao grupo, "ser bem recebida", "estar junto", a solidariedade, o "lidar melhor com o sofrimento mental", o "medo de ficar sem o grupo" e o "experimentar o novo". As narrativas mostraram quanto o fato de ser mulher, em determinado contexto social, limitou-as em relação às suas escolhas pessoais. Essas mulheres ficaram isoladas no ambiente familiar, dedicando-se às tarefas domésticas ou ao trabalho até que os filhos estivessem crescidos. Entretanto, o que se pôde constatar, depois que começaram a frequentar o Reviver, foi uma transformação em suas vidas. Isso pode ter ocorrido porque o grupo operou como um dispositivo, produzindo novas possibilidades de experimentação. Ao fazer funcioná-las, o grupo rompeu com formas enrijecidas de ser e viver, de mulheres silenciadas e homogeneizadas. Elas encontraram um local onde puderam participar de atividades culturais e de lazer diversas (passeios, festa de carnaval, Dia das Mães etc.). Um espaço em que elas puderam desenvolver a criatividade, vivendo situações novas e desafiadoras: ser artista de teatro, dançar, publicar um livro, passear com amigas, resgatar a alegria e o prazer de viver com o outro. Não serem apenas expectadoras, mas, sim, subirem ao palco e serem protagonistas de suas próprias vidas. No grupo, elas experimentaram outros modos de subjetividade que contribuíram para desmanchar territórios cristalizados.

Andrea Langbecker Dissertação (Mestrado), 2010. Programa de Pós-Graduação em Saúde Coletiva, Faculdade de Medicina de Botucatu, Universidade Estadual Paulista. alangbecker@hotmail.com

\footnotetext{
Palavras-chave: Processo grupal. Grupo dispositivo. Histórias de vida. Saúde. Keywords: Group process. Group device. Stories of life. Health. Palabras clave: Grupo de procesos. Grupo de dispositivos. Historias de vida. Salud.
} 